\title{
Chrysin induces cell apoptosis in human uveal melanoma cells via intrinsic apoptosis
}

\author{
CHUNYAN XUE $^{1 *}$, YUEQIN $\mathrm{CHEN}^{1,2^{*}}$, DAN-NING HU ${ }^{2}$, CODRIN IACOB $^{3}$, \\ CHENGWEI LU ${ }^{4}$ and ZHENPING HUANG ${ }^{1}$
}

\author{
${ }^{1}$ Department of Ophthalmology, Jinling Hospital, School of Medicine, Nanjing University, Nanjing, Jiangsu 210002, \\ P.R. China; ${ }^{2}$ Tissue Culture Center; ${ }^{3}$ Department of Pathology, The New York Eye and \\ Ear Infirmary of Mount Sinai, New York, NY 10003, USA; ${ }^{4}$ Department of Ophthalmology, \\ The First Hospital of Jilin University, Changchun, Jilin 130021, P.R. China
}

Received June 24, 2015; Accepted September 22, 2016

DOI: $10.3892 / \mathrm{ol} .2016 .5251$

\begin{abstract}
Uveal melanoma is the most common intraocular malignant tumor in adults. Chrysin is a flavonoid present in honey, propolis, various plants and herbs. In the present study, the cytotoxic effects of chrysin were investigated on human uveal melanoma cell lines (M17 and SP6.5) and associated signaling pathways, and a comparison to the effects on normal ocular cells [scleral fibroblasts and retinal pigment epithelial (RPE) cells] was performed. The effects of chrysin on cell viability were assessed by 3-(4,5-dimethylthiazol-2-yl)-2,5-diphenyltetrazolium bromide assay. Cell apoptosis was determined by using terminal deoxynucleotidyl transferase mediated dUTP nick end-labeling assay. Mitochondrial permeability was determined by JC-1 fluorescein analysis. Cytosol cytochrome $c$ levels, and the activities of caspase-3, -8 and -9 were measured by enzyme-linked immunosorbent assay or colorimetric assay. Chrysin reduced the viability of cultured human melanoma cells in a dose-dependent manner $(0,10,30$ and $100 \mu \mathrm{M})$ with $\mathrm{IC}_{50}$ at 28.3 and $35.8 \mu \mathrm{M}$ in SP6.5 and M17 cell lines, respectively. Chrysin at 30-100 $\mu \mathrm{M}$ levels selectively reduced the viability of melanoma cells without affecting the viability of scleral fibroblasts and RPE cells. Chrysin increased mitochondrial permeability, the levels of cytosol cytochrome $c$, and caspase-9 and -3 activities, but not capase- 8 activity in uveal melanoma cells. The results of the present study indicate that chrysin induces apoptosis of human uveal melanoma cells via the mitochondrial signaling pathway
\end{abstract}

Correspondence to: $\mathrm{Dr}$ Zhenping Huang, Department of Ophthalmology, Jinling Hospital, School of Medicine, Nanjing University, 305 East Zhongshan Road, Nanjing, Jiangsu 210002, P.R. China

E-mail: hzpjlyy@hotmail.com

\section{${ }^{*}$ Contributed equally}

Key words: chrysin, apoptosis, uveal melanoma, cytochrome $c$, caspase-3, caspase-9 and suggest that chrysin may be a promising agent in the treatment of uveal melanoma.

\section{Introduction}

Uveal melanoma, with an incidence of 6-7 cases per million individuals annually in the United States, is the most common intraocular malignant tumor in adults (1). It develops in one of the most capillary-rich tissues of the body and has a high mortality due to a strong preference for metastases in the liver (2). Uveal melanoma responds poorly to chemotherapy (2). Therefore, the mortality of uveal melanoma is high, at $31 \%$ within 5 years of diagnosis, $45 \%$ within 15 years and $49 \%$ within 25 years (2). The majority of uveal melanoma patients die within 6 months of liver metastasis, with a median survival time of 3.6 months $(2,3)$. Therefore, it is urgently required to identify a novel treatment to inhibit the proliferation, migration, invasion and metastasis of uveal melanoma cells.

Flavonoids are a family of polyphenolic compounds synthesized by plants with a similar structure, which are categorized into anthocyanidins, flavanols, flavanones, flavonols, flavones and isoflavones according to their functional groups (4). Chrysin, a naturally active compound of the flavone group, shares a common flavone structure with additional hydroxyls at positions 5 and 7 of the A ring (Fig. 1A and $\mathrm{B}$ ), and the presence of at least two hydroxyl groups in positions 3, 5 and 7 of the A ring is reported to be necessary to confer pro-apoptotic activity (4). Chrysin is present in honey, propolis, and other plants and herbs (5). Chrysin was initially identified for its anti-oxidant effects and has been shown to possess cancer chemopreventive and anti-tumor effects (6-8). It inhibits proliferation and induces apoptosis in a variety of cancer cells in vitro, including cells from the prostate, skin, breast, lung, cervix, thyroid cancer and leukemia (5,8-22). However, to the best of our knowledge, the effects of chrysin on uveal melanoma cells have not been previously studied.

The purpose of the present study was to investigate the cytotoxic effects of chrysin on human uveal melanoma cells in vitro and compare to those on normal human scleral fibroblasts and retinal pigment epithelial (RPE) cells. The effects of 


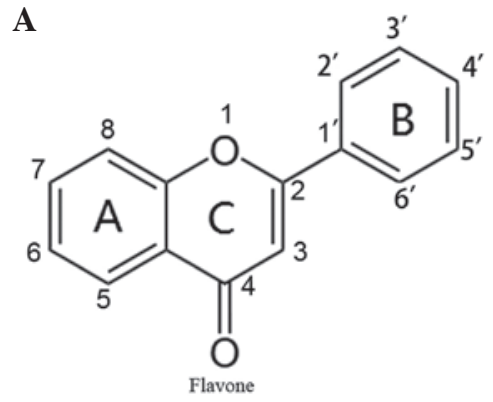<smiles>O=c1cc(-c2ccccc2)oc2cc(O)cc(O)c12</smiles>

Figure 1. Chemical structures of flavones and chrysin. (A) Common chemical structure of flavones. Flavones have a common chemical structure consisting of fused $\mathrm{A}$ and $\mathrm{C}$ rings, and a phenyl $\mathrm{B}$ ring attached to position 2 of the $\mathrm{C}$ ring. (B) Chrysin is one of the flavones and shares a common flavone structure with hydroxyls at position 5 and 7 of the A ring.

chrysin on mitochondrial permeability, cytochrome $c$, and the activities of caspase- $3,-8$ and -9 were also studied to elucidate the signaling pathway involved in chrysin-induced apoptosis of human uveal melanoma cells.

\section{Materials and methods}

Reagents. Chrysin, 3-(4,5-dimethylthiazol-2-yl)-2,5-diphenyltetrazolium bromide (MTT) and dimethyl sulfoxide (DMSO) were purchased from Sigma-Aldrich (EMD Millipore, Billerica, MA, USA). Dulbecco's modified Eagle's medium (DMEM), fetal bovine serum (FBS), phosphate-buffered saline (PBS), 0.05\% trypsin- $0.02 \%$ EDTA solution, and gentamicin were purchased from Gibco (Thermo Fisher Scientific, Inc., Waltham, MA, USA). Cytochrome $c$ enzyme-linked immunosorbent assay (ELISA) and caspase-3 colorimetric assay kits were purchased from EMD Millipore. Caspase- 8 and -9 colorimetric activity assay kits were purchased from R\&D Systems, Inc. (Minneapolis, MN, USA).

Cell culture. The effects of chrysin were investigated in two human uveal melanoma cell lines (SP6.5 and M17) and compared to the effects on two distinct normal cell lines [human retinal pigment epithelial (RPE) cells and scleral fibroblasts]. The human M17 melanoma cell line, RPE cells and scleral fibroblasts were established in the Tissue Culture Center of the New York Eye and Ear Infirmary (New York, NY, USA) as previously reported (23). The SP6.5 melanoma cell line was isolated from a primary choroidal melanoma patient and was provided by Dr. Guy Pelletier (Research Center of Immunology, Quebec, Canada) (24). All melanoma cells, RPE cells and fibroblasts were cultured with DMEM, supplemented with $10 \% \mathrm{FBS}$ and gentamicin $(50 \mu \mathrm{g} / \mathrm{ml})$. Cells were incubated at $37^{\circ} \mathrm{C}$ in a $\mathrm{CO}_{2}$ regulated incubator in a humidified $95 \%$ air $/ 5 \% \mathrm{CO}_{2}$ atmosphere. When cultures reached confluence, cells were detached with trypsin-EDTA solution and passaged. All tissues were obtained with premortem consent in accordance with the laws and regulations in place in the various jurisdictions.

MTT assay for cell viability. MTT assay was performed as previously described (25). Cells $\left(6 \times 10^{3}\right.$ cells/well) were plated into 96 -well plates. Cells were incubated overnight at $37^{\circ} \mathrm{C}$ in a $\mathrm{CO}_{2}$ regulated incubator in a humidified $95 \%$ air $/ 5 \% \mathrm{CO}_{2}$ atmosphere. Chrysin was dissolved in DMSO at a concentration of $20 \mathrm{mM}$ (stock solution). In dose-response studies, $24 \mathrm{~h}$ following plating, chrysin was applied to the cultures at final concentrations of $0,10,30$ and $100 \mu \mathrm{M}$ and cultured for $48 \mathrm{~h}$. A total of $50 \mu 1$ of MTT solution at a concentration of $1 \mathrm{mg} / \mathrm{ml}$ was added to each well. MTT solution was aspirated following $4 \mathrm{~h}$ of incubation at $37^{\circ} \mathrm{C}$ and the produced formazan blue was dissolved in $100 \mu \mathrm{l}$ of DMSO. Absorbance at $540 \mathrm{~nm}$ was measured using a microplate reader (Multiskan MCC/340; Thermo Fisher Scientific, Inc.). The control group measurement was standardized as $100 \%$ viability. The concentration at which cell growth was inhibited by $50 \%$ (the $50 \%$ inhibitory concentration, $\mathrm{IC}_{50}$ ) was determined by linear interpolation. Experiments were performed in triplicate.

To investigate the time-effect of chrysin on uveal melanoma cells, melanoma cells (SP6.5 cell line, 6x10 ${ }^{3}$ cells/well) were plated into 96-well plates and divided into two groups: Chrysin-treated group and untreated group (control group). Subsequently, chrysin was added to the cultures in the treated groups at the concentrations of $30 \mu \mathrm{M}$ following $24 \mathrm{~h}$ of incubation at $37^{\circ} \mathrm{C}$. MTT assay was subsequently performed in treated and untreated groups at $0,6,12,24$ and $48 \mathrm{~h}$ following the addition of chrysin. The results of each treated group were compared to the controls at the identical time point. All measurements were performed in three independent experiments, and each time point was performed in triplicate.

Apoptotic cells detection assay. Cell apoptosis was determined by the terminal deoxynucleotidyl transferase (TdT) mediated dUTP nick end-labeling (TUNEL) assay $(26,27)$ using a TACS.XL In Situ Apoptosis Detection kit (cat. no.4828-30-DK; R \& D Systems, Inc.). The assay was performed according to the manufacturer's protocol. Briefly, cells were cultured on chamber slides and analyzed $48 \mathrm{~h}$ following treatment with 10,30 and $100 \mu \mathrm{M}$ chrysin. Cells were fixed, incubated with $3 \% \mathrm{H}_{2} \mathrm{O}_{2}$ /methanol and permeabilized. Slides were covered by Labeling Reaction mix (R \& D Systems, Inc.) and incubated for $1 \mathrm{~h}$ at $37^{\circ} \mathrm{C}$ in a dark humidified chamber, followed by incubation with anti-BrdU antibody (1:50; cat. no. 4828-30-DK; TACS.XL In Situ Apoptosis Detection kit; R \& D Systems, Inc.) at $37^{\circ} \mathrm{C}$ for $1 \mathrm{~h}$. The slides were treated with streptavidin-horseradish peroxidase solution(R \& D Systems, Inc.) for $10 \mathrm{~min}$, followed by staining with 3,3'-diaminobenzidine (DAB) substrate for $5 \mathrm{~min}$. The samples were mounted and analyzed under a light microscope, where the apoptotic cells 
could be detected as highly condensed shrunken dark brown cells. A total of 200 cells were counted in each group $(0,10$, 30 and $100 \mu \mathrm{M}$ chrysin treatment groups). The experiment was repeated independently a total of three times.

Mitochondrial transmembrane potential assessment (MTP) by JC-1 staining. MTP was measured by a Mitochondria Staining kit (cat. no. T4069; Sigma-Aldrich; EMD Millipore), which employed JC-1 (5,5',6,6'-tetrachloro-1,1',3,3'-etraethylbenzimidazol-carbocyanine iodine), a sensitive fluorescent dye, as the probe. Uveal melanoma cells (SP6.5 cell line) were plated into 96-well plates with black wells (Corning Incorporated, Corning, NY, USA) at a density of $8 \times 10^{3}$ cells/well. Following $24 \mathrm{~h}$ of incubation at $37^{\circ} \mathrm{C}$, cells were treated with chrysin at various concentrations $(0,10,30$ and $100 \mu \mathrm{M})$ at $37^{\circ} \mathrm{C}$ for $48 \mathrm{~h}$. JC-1 (at final concentration $12.5 \mu \mathrm{g} / \mathrm{ml}$ ) was added and incubated at $37^{\circ} \mathrm{C}$ in the dark for $15 \mathrm{~min}$. JC-1 and culture medium were aspirated and cells were washed three times with PBS. Cells were immediately observed by fluorescence microplate reader (Spectraflour Plus; Tecan Group Ltd., Männedorf, Switzerland). Settings of 485-nm (excitation) and 590-nm (emission) were used to measure red fluorescence; 485-nm (excitation) and 535-nm (emission) were used to measure green fluorescence. The detection is based on the accumulation of the dye and its fluorescence in the mitochondria. The accumulated dye appears as red fluorescence located in the undamaged mitochondria, whereas the dye remains as monomers in the cytoplasm with diffuse green fluorescence in cells with damaged MTP (28). The results (red fluorescence/green fluorescence ratio, $\mathrm{R} / \mathrm{G}$ ratio) were expressed as a percentage of the controls (cells not treated with chrysin). This experiment was performed a total of three independent times.

Cytochrome c release assay. To detect the release of mitochondrial cytochrome $c$, uveal melanoma cells (SP6.5 cell line, $4 \times 10^{5}$ cells/well) were plated into 6 -well plates. A total of $24 \mathrm{~h}$ later, chrysin was added at various concentrations $(0,10,30$ and $100 \mu \mathrm{M})$. Following $2 \mathrm{~h}$ of incubation at $37^{\circ} \mathrm{C}$, the cells were harvested. The cells were washed with cold PBS three times, treated with $0.02 \%$ EDTA solution and scraped from the well. Subsequently, cells were counted and centrifuged at $400 \mathrm{x} g$ at $4^{\circ} \mathrm{C}$ for $5 \mathrm{~min}$, and the cell pellets were collected. Following cell lysis and centrifugation at $1,000 \mathrm{xg}$ at $4^{\circ} \mathrm{C}$ for $10 \mathrm{~min}$, the supernatant (cytosol and mitochondria) was collected and centrifuged at $10,000 \times \mathrm{g}$ at $4^{\circ} \mathrm{C}$ for $20 \mathrm{~min}$. The pellets (mitochondria) and the supernatant (cytosol) were then collected separately. A cytochrome $c$ ELISA kit (EMD Millipore) was used to measure the level of cytochrome $c$ in the cytosol and the procedure was performed according to the manufacturer's protocol. The cytochrome $c$ level was demonstrated as a percentage of the controls (cells not treated with chrysin).

Caspase-3, caspase- 8 and caspase-9 colorimetric assay. Melanoma cells (SP6.5 cell line, $4 \times 10^{5}$ cells/well) were plated into 6-well plates, and chrysin was added at various concentrations $(0,10,30$ and $100 \mu \mathrm{M})$ following $24 \mathrm{~h}$ of incubation at $37^{\circ} \mathrm{C}$. A total of $2 \mathrm{~h}$ later, cells were washed with cold PBS and collected. Subsequently, the cells were counted and centrifuged at $400 \mathrm{x} g$ at $4^{\circ} \mathrm{C}$ for $5 \mathrm{~min}$, and the cell pellets were collected.
The cells were lysed using cell extraction buffer (BioSource; Thermo Fisher Scientific, Inc.) with protease inhibitor cocktail (Sigma-Aldrich; EMD Millipore) and phenylmethane sulfonyl fluoride (BioSource; Thermo Fisher Scientific, Inc.), incubated on ice for $30 \mathrm{~min}$, and vortexed for $30 \mathrm{sec}$. The lysates were centrifuged at $15,000 \times \mathrm{g}$ for $10 \mathrm{~min}$ at $4^{\circ} \mathrm{C}$. The supernatant was stored at $-70^{\circ} \mathrm{C}$ until analysis. The levels of caspase-3, -8 , and -9 in cell lysates were measured by specific colorimetric kits in accordance with the manufacturer's protocol. A microplate reader at $405 \mathrm{~nm}$ was used to measure the optical density. Caspase-3, caspase- 8 and caspase- 9 activities were demonstrated as a percentage of the controls (cells not treated with chrysin). This measurement was performed independently three times.

Statistical analysis. Data was analyzed using SPSS version 17.0 (SPSS Inc., Chicago, IL, USA). Significance was evaluated using one-way analysis of variance and the least significant difference method in comparison of data of more than two groups and Student's $t$-test for of comparison data between two groups. $\mathrm{P}<0.05$ was considered to indicate a statistically significant difference.

\section{Results}

Effects of chrysin on viability of melanoma and normal cells. Chrysin induced cell death in cultured human uveal melanoma cells in a dose-dependent manner (Figs. 2 and 3). There was a significant difference in cell viability between melanoma cells (M17 and SP6.5) treated or untreated with chrysin $(\mathrm{P}<0.001)$ at $30-100 \mu \mathrm{M}$ levels. The $\mathrm{IC}_{50}$ dose of chrysin for M17 and SP6.5 at $48 \mathrm{~h}$ was 35.8 and $28.3 \mu \mathrm{M}$, respectively. Chrysin at 10-100 $\mu \mathrm{M}$ levels did not affect the cell viability of cultured human RPE cells or fibroblasts. These results demonstrated that chrysin at $30-100 \mu \mathrm{M}$ selectively reduced the viability of melanoma cells without affecting RPE cells or fibroblasts.

Time-effect study demonstrated that chrysin at $30 \mu \mathrm{M}$ decreased the viability of uveal melanoma cells (SP6.5) in a time-dependent manner from 6 to $48 \mathrm{~h}$ (data not shown). There was a significant difference in cell viability at various time points between the treated and untreated group $(\mathrm{P}<0.001)$.

Chrysin induced apoptosis of melanoma cells. TUNEL analysis was used for the detection of cell apoptosis. Normal cells were stained by methyl green and were green in color. The nuclei of apoptotic cells were stained by DAB and were dark-brown in color. Chrysin significantly increased the apoptotic rate of uveal melanoma cells in all treated cultures compared to the control ( $\mathrm{P}<0.001$; Fig. 4).

Effects of chrysin on MTP in melanoma cells. For cells cultured with JC-1, red fluorescence was due to a potential-dependent aggregation of JC-1 in the mitochondria. Green fluorescence observed in the cytosol following mitochondrial membrane depolarization reflected the monomeric form of JC-1. Chrysin significantly decreased the $\mathrm{R} / \mathrm{G}$ ratio in a dose-dependent manner (compared to the control; $\mathrm{P}<0.001$ at all tested levels), which revealed that chrysin caused damage to the MTP in uveal melanoma cells (Fig. 5). 

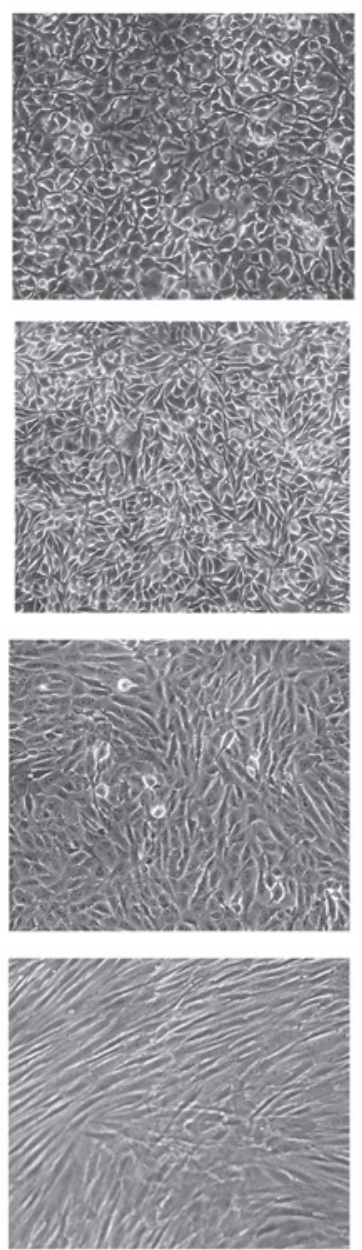

Control
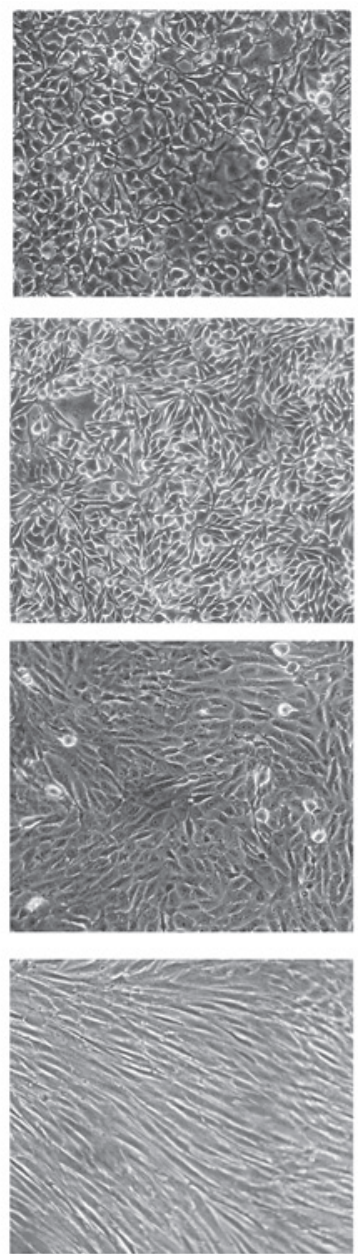

$10 \mu \mathrm{M}$
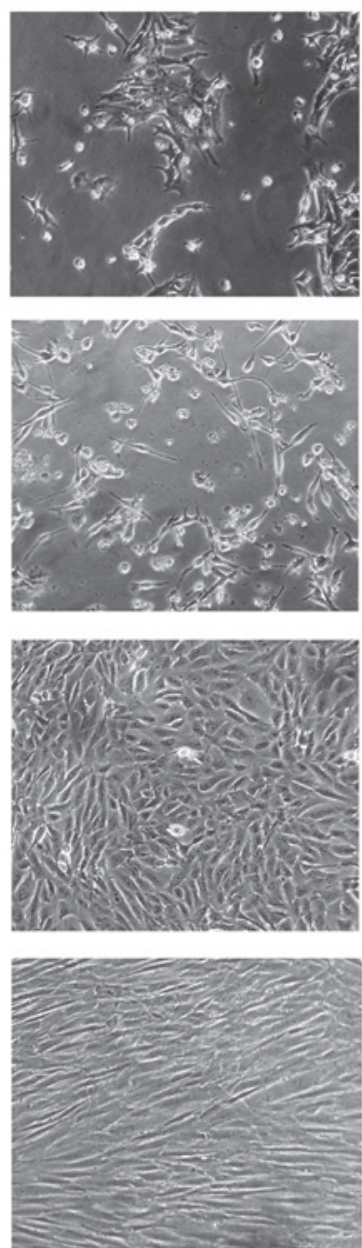

$30 \mu \mathrm{M}$

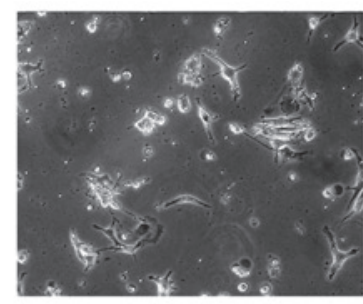

SP6.5

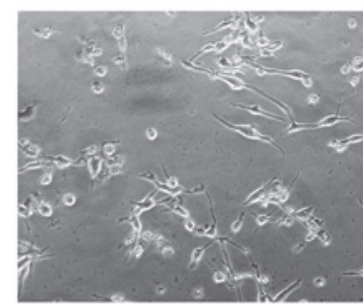

M17

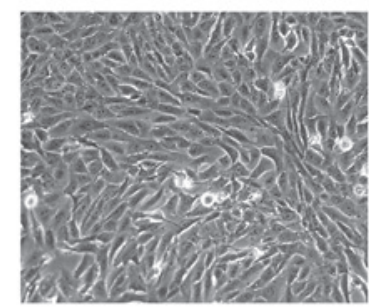

RPE cells

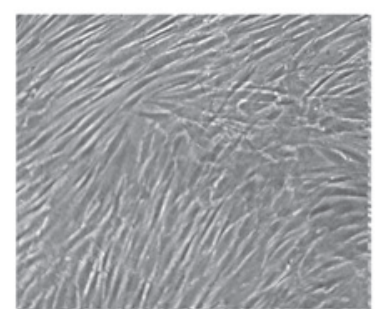

Fibroblast

$100 \mu \mathrm{M}$

Figure 2. Effect of chrysin on the viability of uveal melanoma cells, human RPE cells and scleral fibroblasts. Phase-contrast photomicrograph of uveal melanoma cells, human RPE cells and fibroblasts treated with various concentrations of chrysin. Human uveal melanoma cells (SP6.5 and M17), human RPE cells and scleral fibroblasts were seeded into 24 -well plates at density of $8 \times 10^{4} /$ well and treated with chrysin at 10,30 and $100 \mu \mathrm{M}$ for $48 \mathrm{~h}$. Chrysin at 30 and $100 \mu \mathrm{M}$ significantly decreased the number of viable melanoma cells, whereas did not affect the viability of human RPE cells and scleral fibroblasts. RPE, retinal pigment epithelial.

Effects of chrysin on the release of cytochrome $c$ in cytosol. Chrysin caused an increase of cytosol cytochrome $c$ levels in melanoma cells in a dose-dependent manner (compared to the control; $\mathrm{P}=0.25$ at the levels of $10 \mu \mathrm{M} ; \mathrm{P}<0.001$ at the levels of 30-100 $\mu \mathrm{M}$ ) (Fig. 6).

Effects of chrysin on caspase-3, caspase-8 and caspase-9 activities in melanoma cells. Chrysin increased the activities of caspase-3 and -9 in melanoma cells in a dose-dependent manner (Fig. 7A and B). Chrysin at 30-100 $\mu \mathrm{M}$ levels resulted in a significant increase of caspase- 3 and -9 activities in melanoma cells $(\mathrm{P}<0.001)$. In uveal melanoma cells treated with $100 \mu \mathrm{M}$ chrysin, an $\sim 4$.11-fold and 4.58-fold increase in caspase-3 and caspase- 9 activities was noted, respectively. There was no significant change in caspase-8 activity following treatment with chrysin at 10-100 $\mu \mathrm{M}$ levels (Fig. 7C).

\section{Discussion}

Chrysin has been demonstrated to possess cancer chemopreventive activity through inhibition of cell proliferation $(10,18)$, and induce apoptosis in various malignant cancer cells $(5,11,15-17,20-22)$.

It has been reported that chrysin is cytotoxic in murine and human cutaneous melanoma cells in vitro $(9,10)$. However, to the best of our knowledge, the effect of chrysin on uveal melanoma cells has not been previously reported. Cutaneous melanomas differ from uveal melanomas not only in the etiologic and epidemiologic aspects, but also in their molecular biological patterns. The majority of cutaneous melanomas occur in areas exposed to sun radiation, whereas the majority of uveal melanomas occur in the posterior segment of the eye, which is not exposed to significant sun radiation. Chromosomal assessment and molecular biological and epidemiological studies demonstrate that cutaneous melanomas differ from uveal melanomas (29-34), whereas conjunctival melanomas appear to have more similarities to cutaneous than uveal melanomas $(32,34)$. The primary underlying biological differences between uveal and cutaneous melanomas may be associated with various gene mutations and differing microenvironments. Therefore, uveal melanomas and cutaneous melanomas should be considered as two 
A

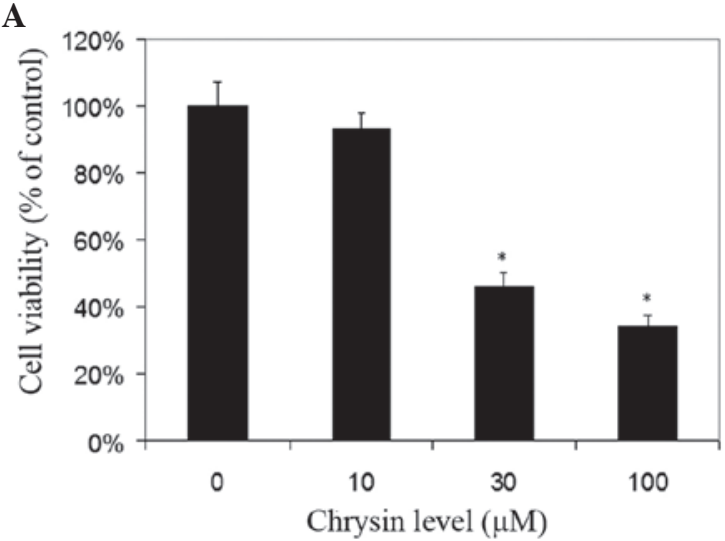

C

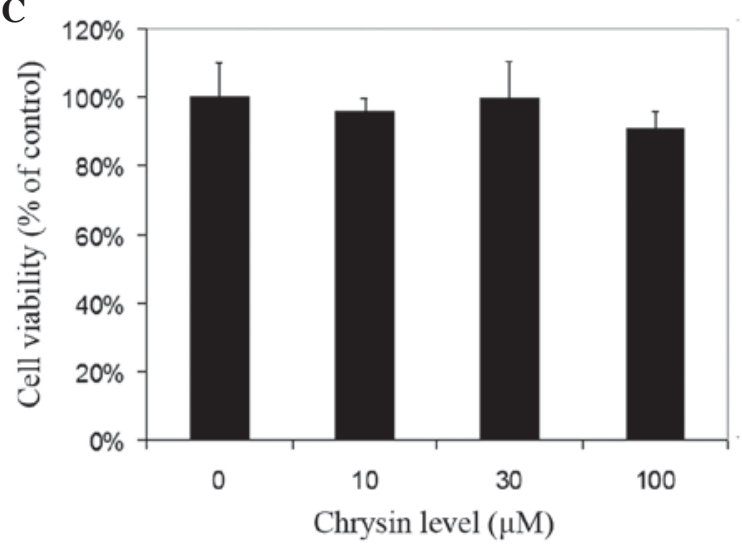

B

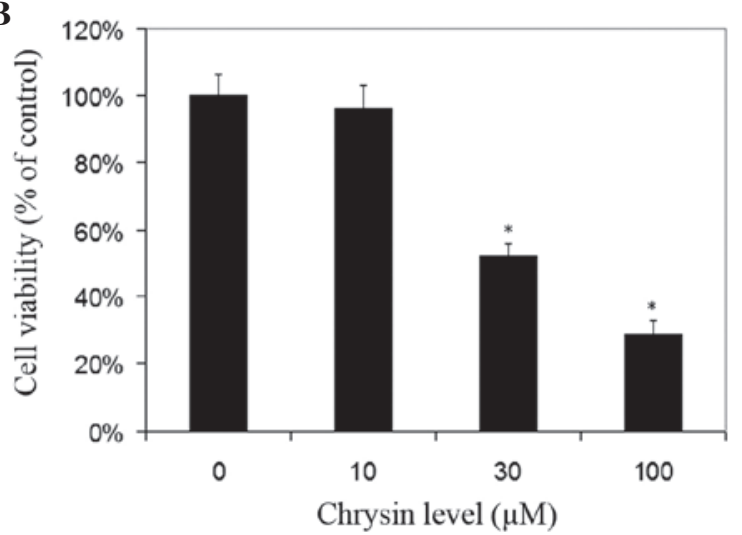

D

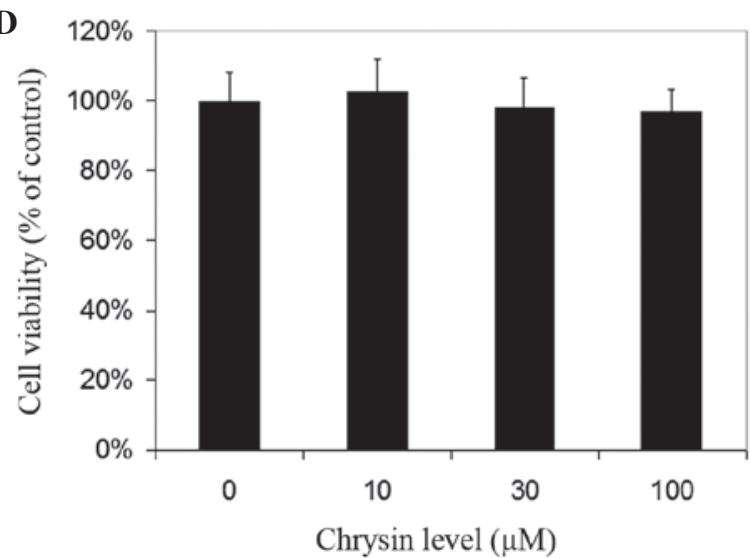

Figure 3. Dose effect of chrysin on the viability of uveal melanoma cells, human RPE cells and scleral fibroblasts. Uveal melanoma cells (A) SP6.5, (B) M17, (C) human RPE cells (D) and scleral fibroblasts were seeded into 96-well plates and treated with chrysin at various doses for 48 h, and cell survival was determined by MTT assay. Data are presented as the mean \pm standard deviation (percentage of the controls) from three independent experiments, each in triplicate. Chrysin at 30-100 $\mu \mathrm{M}$ levels selectively reduced the viability of uveal melanoma cells, without affecting the viability of uveal melanocytes and fibroblasts. "P<0.05 vs. the control (cells cultured without chrysin). RPE, retinal pigment epithelial.

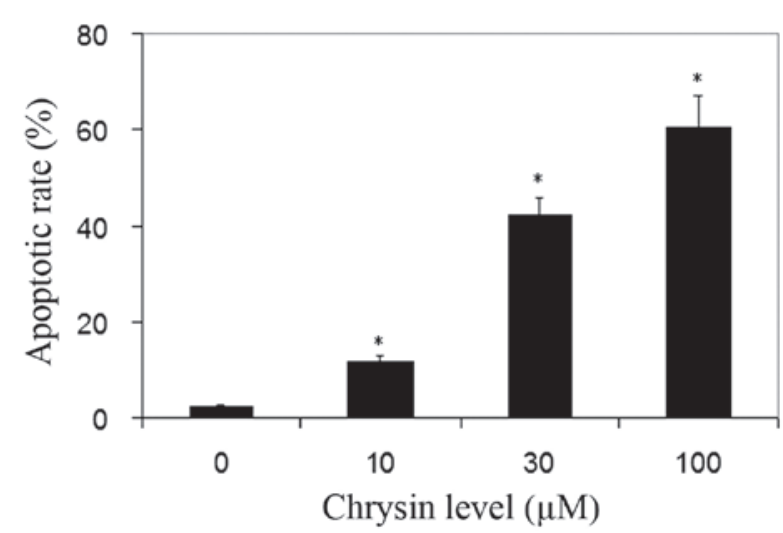

Figure 4. Effect of chrysin on melanoma cell apoptosis measured by TUNEL assay. Melanoma cells (SP6.5) were treated by chrysin at 0-100 $\mu \mathrm{M}$ for $48 \mathrm{~h}$, and the extent of apoptosis was determined by TUNEL assay. Chrysin significantly increased the rate of apoptosis in three independent experiments. Data are presented as the mean \pm standard deviation from three independent experiments. " $\mathrm{P}<0.05$ vs. the control (cells cultured without chrysin). TUNEL, terminal deoxynucleotidyl transferase mediated dUTP nick end labeling.

distinct types of cancer, and each disease has a unique oncogenetic signaling pathway for the development of the tumor. Additional studies are required to investigate the pathogenesis and relevant novel treatments for each type of melanoma.

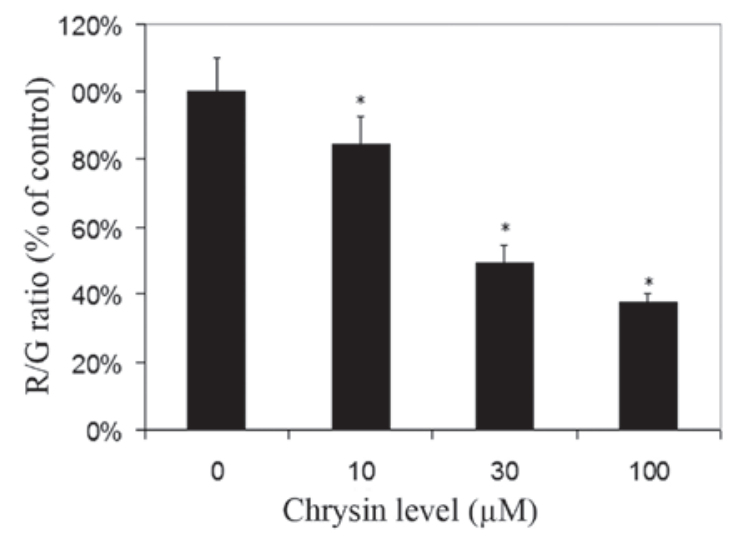

Figure 5. Effect of chrysin on melanoma cell mitochondrial membrane potential. Melanoma cells (SP6.5) were treated by chrysin at 0, 10, 30 and $100 \mu \mathrm{M}$ for $48 \mathrm{~h}$, and the MTP was determined by JC-1 staining. The results ( $\mathrm{R} / \mathrm{G}$ ratio) were expressed as the percentage of cells not treated with chrysin (mean \pm standard deviation from three independent experiments). Chrysin reduced the $\mathrm{R} / \mathrm{G}$ ratio and decreased the MTP in uveal melanoma cells in a dose-dependent manner. ${ }^{*} \mathrm{P}<0.05$ vs. the control (cells cultured without chrysin). R/G ratio, red fluorescence/green fluorescence ratio; MTP, mitochondrial transmembrane potential.

In the present study, chrysin caused a significant decrease in the viability of human melanoma cell lines (M17 and SP6.5) at concentrations of $30-100 \mu \mathrm{M}$ in a dose- and time-dependent 


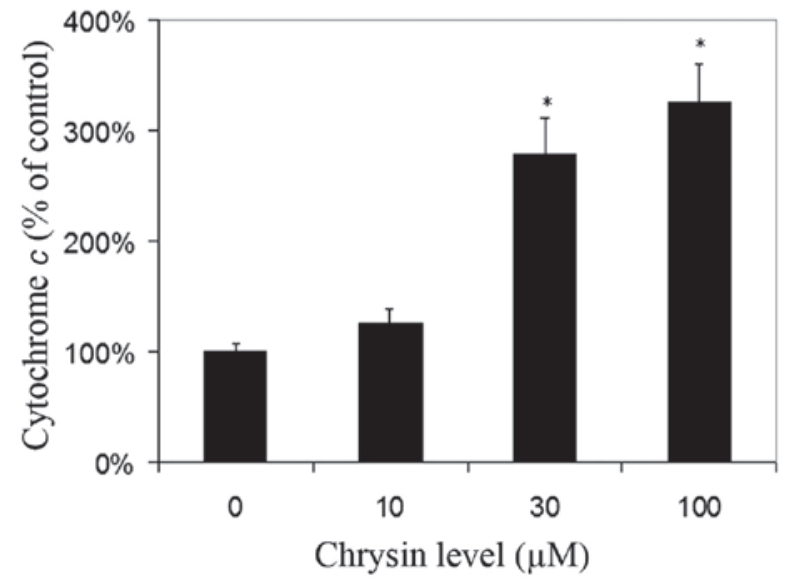

Figure 6. Effect of chrysin on melanoma cell cytosol cytochrome $c$ levels. Uveal melanoma cells (SP6.5) were treated with chrysin at $0,10,30$ and $100 \mu \mathrm{M}$ for $2 \mathrm{~h}$. Cells were collected and lysed, and the cytosol was extracted. The cytochrome $c$ level in the cytosol was measured using a cytochrome $c$ enzyme-linked immunosorbent assay kit. Cytosol cytochrome $c$ level in chrysin-treated cells at various concentrations was expressed as a percentage of the controls (mean \pm standard deviation from three independent experiments). Chrysin increased the level of cytosol cytochrome $c$ in a dose-dependent manner. ${ }^{*} \mathrm{P}<0.05$ vs. the control (cells cultured without chrysin).

manner, whereas viability of normal cells (scleral fibroblasts and RPE cells) was not affected. The results of the present study suggested that chrysin may have specific anticancer activity in uveal melanoma cells.

In the present study, cell apoptosis was determined by TUNEL analysis. Apoptosis is characterized by a number of intracellular phenomena, including membrane blebbing, chromatin condensation and nuclear DNA fragmentation. Detection of DNA fragmentation is a widely accepted method to assay for apoptosis $(26,27)$. Fragmentation may be visualized by and detected in situ by incorporating labeled nucleotides onto the free $3^{\prime} \mathrm{OH}$ ends of the fragments using TdT enzyme followed by detection of the labeled molecules. This assay allows distinction between apoptotic cells (with brown colored nuclei) and normal cells (non-specific stained green colored nuclei). For the cells treated with chrysin, cells stained with DAB (indicating apoptotic changes) were significantly increased compared to the controls. This is consistent with previous studies, which have reported an apoptosis-induction effect of chrysin in prostate cancer, lung cancer, leukemia and cutaneous melanoma cells $(4,5,9,12)$.

There are two distinct apoptosis signaling pathways: Intrinsic and extrinsic pathways (35). For the intrinsic apoptosis signaling pathway, loss of MTP, which may be recognized in living cells using JC-1, is an early event (28). Loss of MTP induces the increase of mitochondrial membrane permeability, which leads to the release of cytochrome $c$ from the mitochondria to the cytoplasm (36). When cytochrome $c$ is released to the cytoplasm, caspase- 9 is activated. Subsequently, the activated caspase-9 in turn promotes activation of caspase-3, resulting in apoptosis of the tumor cells (36). Therefore, the intrinsic signaling pathway is also called the mitochondrial apoptotic pathway. For the extrinsic apoptosis signaling pathway, various cell death surface receptors are activated following binding to
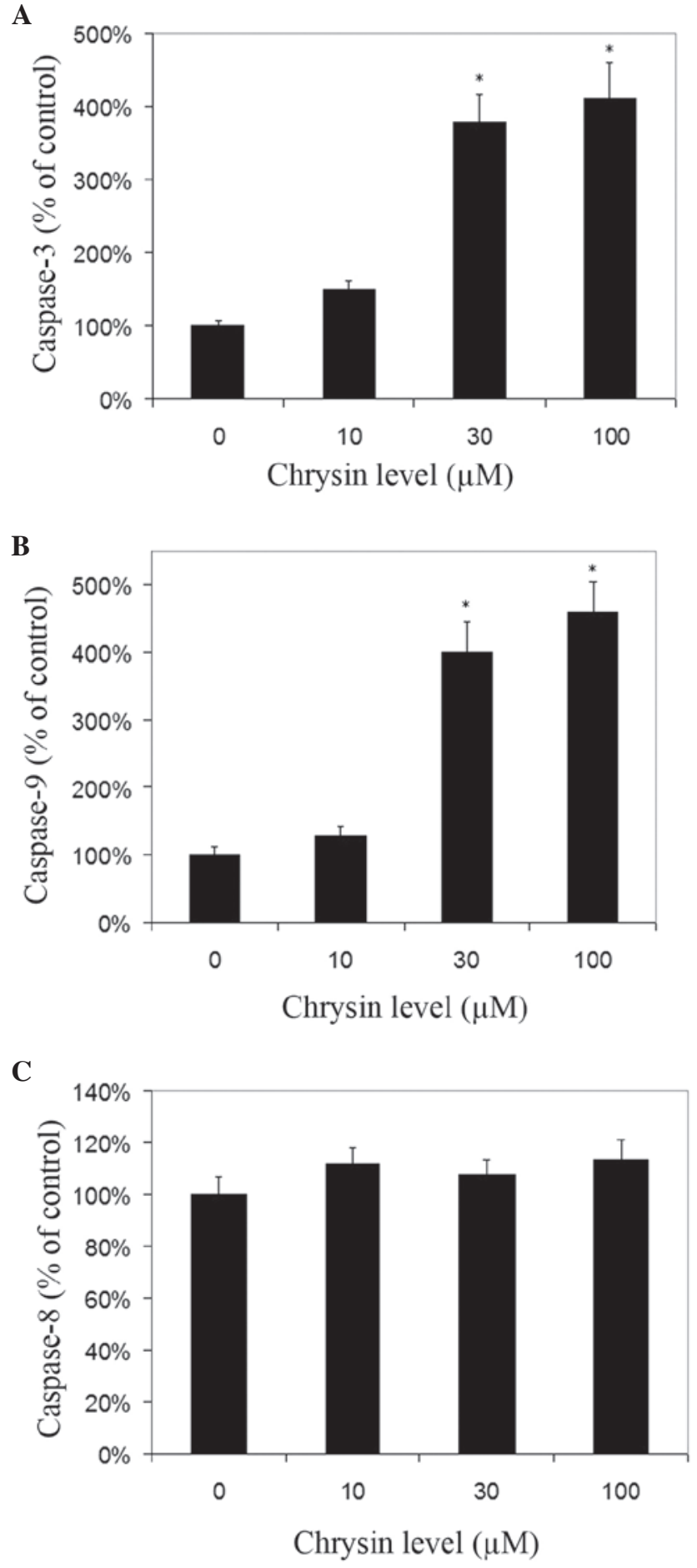

Figure 7. Effects of chrysin on the activation of caspase-3, -8 and -9 in human uveal melanoma cell lines. Uveal melanoma cells (SP6.5) were treated with various concentrations of chrysin $(0-100 \mu \mathrm{M})$ for $2 \mathrm{~h}$. Cells were collected and lysed. The caspase- $3,-8$ and -9 in the lysates was measured using relevant caspase colorimetric assay kits. Caspase- $3,-8$ and -9 levels in chrysin-treated cells at various concentrations were expressed as a percentage of the controls (mean \pm standard deviation) from three independent experiments. Chrysin significantly increased the activities of (A) caspase-3 and (B) caspase-9 at 30-100 $\mu \mathrm{M}$ levels, but not (C) caspase-8. "P<0.05 vs. the control (cells cultured without chrysin).

the relevant ligands (35). Following this, the activated death receptors activate caspase- 8 by binding to the secondary adaptor protein, which results in the cleavage of caspase- 3 and cell apoptosis (35). 
Previous studies have revealed that chrysin induces apoptosis of malignant cells through the mitochondrial signaling pathway $(9,12)$. However, Monasterio et al (4) reported that chrysin induced human leukemia U937 cell apoptosis in a manner that required the activation of caspase- 8 instead of caspase-9, which is the extrinsic signaling pathway. This indicates that the apoptotic signaling pathway involved in chrysin-induced apoptosis may be cell-type specific.

In the present study, chrysin caused the loss of MTP, increased the levels of cytosol cytochrome $c$ and the activities of caspase- 9 and -3 in a dose-dependent manner. However, the activities of caspase- 8 were not altered following treatment with chrysin. These observations are consistent with previous reports $(9,12)$, that suggested that chrysin induced apoptosis in cutaneous melanoma cells and lung adenocarcinoma epithelial cells primarily via the intrinsic mitochondrial signaling pathway.

Two uveal melanoma cell lines were investigated in the present study (M17 and SP6.5 cell lines). Both cell lines were isolated from Caucasian primary choroidal melanoma patients, and have comparable growth capacity and pigmentation. However, epigenetic studies observed that the SP6.5 cell line differed from the M17 cell line in that the decrease of miR-137 expression was more pronounced in SP6.5 than in M17 (37).

In summary, chrysin significantly decreased cell viability and induced apoptosis of human uveal melanoma cells without affecting normal cell viability, which suggested that chrysin had a selective and potent pro-apoptotic effect on human uveal melanoma cells in vitro. This effect was primarily through the intrinsic mitochondrial signaling pathway. These encouraging in vitro findings suggest that chrysin may be a promising agent worthy of being investigated for the treatment of uveal melanoma.

\section{Acknowledgments}

The authors thank Dr. Guy Pelletier (Research Center of Immunology, Quebec, Canada) for providing the SP6.5 melanoma cell line.

\section{References}

1. Hu DN, Yu GP, McCormick SA, Schneider S and Finger PT: Population-based incidence of uveal melanoma in various races and ethnic groups. Am J Ophthalmol 140: 612-617, 2005.

2. Kujala E, Mäkitie T and Kivelä T: Very long-term prognosis of patients with malignant uveal melanoma. Invest Ophthalmol Vis Sci 44: 4651-4659, 2003.

3. Augsburger JJ, Corrêa ZM and Shaikh AH: Effectiveness of treatments for metastatic uveal melanoma. Am J Ophthalmol 148: 119-127, 2009.

4. Monasterio A, Urdaci MC, Pinchuk IV, López-Moratalla N and Martínez-Irujo JJ: Flavonoids induce apoptosis in human leukemia U937 cells through caspase- and caspase-calpain-dependent pathways. Nutr Cancer 50: 90-100, 2004.

5. Samarghandian S, Afshari JT and Davoodi S: Chrysin reduces proliferation and induces apoptosis in the human prostate cancer cell line pc-3. Clinics (Sao Paulo) 66: 1073-1079, 2011.

6. Cho H, Yun CW, Park WK, Kong JY, Kim KS, Park Y, Lee S and Kim BK: Modulation of the activity of pro-inflammatory enzymes, COX-2 and iNOS, by chrysin derivatives. Pharmacol Res 49: 37-43, 2004.

7. Woodman OL and Chan ECh: Vascular and anti-oxidant actions of flavonols and flavones. Clin Exp Pharmacol Physiol 31: 786-790, 2004

8. Khoo BY, Chua SL and Balaram P: Apoptotic effects of chrysin in human cancer cell lines. Int J Mol Sci 11: 2188-2199, 2010
9. Pichichero E, Cicconi R, Mattei Mand Canini A: Chrysin-induced apoptosis is mediated through p38 and Bax activation in B16-F1 and A375 melanoma cells. Int J Oncol 38: 473-483, 2011.

10. Pichichero E, Cicconi R, Mattei M, Muzi MG and Canini A: Acacia honey and chrysin reduce proliferation of melanoma cells through alterations in cell cycle progression. Int J Oncol 37: 973-981, 2010.

11. Yang B, Huang J, Xiang T, Yin X, Luo X, Huang J, Luo F, $\mathrm{Li} \mathrm{H}, \mathrm{Li} \mathrm{H}$ and Ren G: Chrysin inhibits metastatic potential of human triple-negative breast cancer cells by modulating matrix metalloproteinase-10, epithelial to mesenchymal transition, and PI3K/Akt signaling pathway. J Appl Toxicol 34: 105-112, 2014.

12. Samarghandian S, Nezhad MA and Mohammadi G: Role of caspases, Bax and Bcl-2 in chrysin-induced apoptosis in the A549 human lung adenocarcinoma epithelial cells. Anticancer Agents Med Chem 14: 901-909, 2014.

13. Lee SJ, Yoon JH and Song KS: Chrysin inhibited stem cell factor (SCF)/c-Kit complex-induced cell proliferation in human myeloid leukemia cells. Biochem Pharmacol 74: 215-225, 2007.

14. Sak K: Cytotoxicity of dietary flavonoids on different human cancer types. Pharmacogn Rev 8: 122-146, 2014.

15. Yu XM, Phan T, Patel PN, Jaskula-Sztul R and Chen H: Chrysin activates Notch1 signaling and suppresses tumor growth of anaplastic thyroid carcinoma in vitro and in vivo. Cancer 119: 774-781, 2013.

16. Shao JJ, Zhang AP, Qin W, Zheng L, Zhu YF and Chen X: AMP-activated protein kinase (AMPK) activation is involved in chrysin-induced growth inhibition and apoptosis in cultured A549 lung cancer cells. Biochem Biophys Res Commun 423: 448-453, 2012.

17. Phan T, Yu XM, Kunnimalaiyaan M and Chen H: Antiproliferative effect of chrysin on anaplastic thyroid cancer. J Surg Res 170: 84-88, 2011.

18. Pilátová M, Stupáková V, Varinská L, Sarisský M, Mirossay L, Mirossay A, Gál P, Kraus V, Dianisková K and Mojzis J: Effect of selected flavones on cancer and endothelial cells. Gen Physiol Biophys 29: 134-143, 2010.

19. Hong TB, Rahumatullah A, Yogarajah T, Ahmad M and Yin KB: Potential effects of chrysin on MDA-MB-231 cells. Int J Mol Sci 11: 1057-1069, 2010.

20. Weng MS, Ho YS and Lin JK: Chrysin induces G1 phase cell cycle arrest in C6 glioma cells through inducing p21Waf1/Cip1 expression: Involvement of p38 mitogen-activated protein kinase. Biochem Pharmacol 69: 1815-1827, 2005.

21. Woo KJ, Jeong YJ, Park JW and Kwon TK: Chrysin-induced apoptosis is mediated through caspase activation and Akt inactivation in U937 leukemia cells. Biochem Biophys Res Commun 325: 1215-1222, 2004

22. Zhang T, Chen X, Qu L, Wu J, Cui R and Zhao Y: Chrysin and its phosphate ester inhibit cell proliferation and induce apoptosis in Hela cells. Bioorg Med Chem 12: 6097-6105, 2004.

23. Hu DN, McCormick SA, Ritch R and Pelton-Henrion K: Studies of human uveal melanocytes in vitro: Isolation, purification and cultivation of human uveal melanocytes. Invest Ophthalmol Vis Sci 34: 2210-2219, 1993.

24. Soulieres D, Rousseau A, Deschenes J, Tremblay M, Tardif M and Pelletier G: Characterization of gangliosides in human uveal melanoma cells. Int J Cancer 49: 498-503, 1991.

25. Lu C, Song E, Hu DN, Chen M, Xue C, Rosen R and McCormick SA: Curcumin induces cell death in human uveal melanoma cells through mitochondrial pathway. Curr Eye Res 35: 352-360, 2010.

26. Parthasarathy G and Philipp MT: The MEK/ERK pathway is the primary conduit for Borrelia burgdorferi-induced inflammation and P53-mediated apoptosis in oligodendrocytes. Apoptosis 19: 76-89, 2014.

27. Turgeman T, Kakongi N, Schneider A, Vinokur Y, Teper-Bamnolker P, Carmeli S, Levy M, Skory CD, Lichter A and Eshel D: Induction of Rhizopus oryzae germination under starvation using host metabolites increases spore susceptibility to heat stress. Phytopathology 104: 240-247, 2014.

28. Cossarizza A, Baccarani-Contri M, Kalashnikova G and Franceschi C: A new method for the cytofluorimetric analysis of mitochondrial membrane potential using the J-aggregate forming lipophilic cation 5,5',6,6'-tetrachloro-1,1',3,3'-tetraethylbenzimidazolcarbocyanine iodide (JC-1). Biochem Biophys Res Commun 197: 40-45, 1993.

29. Gilchrest BA, Eller MS, Geller AC and Yaar M: The pathogenesis of melanoma induced by ultraviolet radiation. N Engl J Med 340: 1341-1348, 1999. 
30. Bergman L, Seregard S, Nilsson B, Ringborg U, Lundell G and Ragnarsson-Olding B: Incidence of uveal melanoma in Sweden from 1960 to 1998. Invest Ophthalmol Vis Sci 43: 2579-2583, 2002.

31. Yu GP, Hu DN and McCormick SA: Latitude and incidence of ocular melanoma. Photochem Photobiol 82: 1621-1626, 2006.

32. Spendlove HE, Damato BE, Humphreys J, Barker KT, Hiscott PS and Houlston RS: BRAF mutations are detectable in conjunctival but not uveal melanomas. Melanoma Res 14 449-452, 2004.

33. Vajdic CM, Hutchins AM, Kricker A, Aitken JF, Armstrong BK, Hayward NK and Armes JE: Chromosomal gains and losses in ocular melanoma detected by comparative genomic hybridization in an Australian population-based study. Cancer Genet Cytogenet 144: 12-17, 2003.
34. Hu DN, Yu G, McCormick SA and Finger PT: Population-based incidence of conjunctival melanoma in various races and ethnic groups and comparison with other melanomas. Am J Ophthalmol 145: 418-423, 2008.

35. McConkey DJ: Biochemical determinants of apoptosis and necrosis. Toxicol Lett 99: 157-168, 1998.

36. Kroemer G, Dallaporta B and Resche-Rigon M: The mitochondrial death/life regulator in apoptosis and necrosis. Annu Rev Physiol 60: 619-642, 1998.

37. Chen X, Wang J, Shen H, Lu J, Li C, Hu DN, Dong XD, Yan D and Tu L: Epigenetics, microRNAs, and carcinogenesis: Functional role of microRNA-137 in uveal melanoma. Invest Ophthalmol Vis Sci 52: 1193-1199, 2011. 